\title{
Pseudoaneurysm of the Ascending Aorta Following Bentall Procedure
}

Vaclav Hanak*, Martin Troubil, Petr Santavy and Vladimir Lonsky

Cardiac Surgery Department, University Hospital Olomouc, Czech Republic

*Corresponding author: Vaclav Hanak, Cardiac Surgery Department, University Hospital Olomouc, Czech Republic, Tel: +420608402788; E-mail: hanakvaclav@seznam.cz

Received date: Jul 30, 2016; Accepted date: Aug 07, 2016; Published date: Aug 12, 2016

Copyright: $\odot 2016$ Hanak V, et al. This is an open-access article distributed under the terms of the Creative Commons Attribution License, which permits unrestricted use, distribution, and reproduction in any medium, provided the original author and source are credited.

\section{Abstract}

We report the case of young man with acute aortic dissection type A treated by Bentall operation. Postoperatively the patient was febrile and echocardiography revealed fluid collection around the aortic graft. Indicated surgery revealed sterile perigraft seroma which recurred after reoperation, Corticosteroids were therefore administered. Ten months after the Bentall operation the patient was treated for pneumonia with sepsis and incidentally an asymptomatic aortic pseudoaneurysm was revealed. Successful re-Bentall operation was performed and the patient finally discharged. We presume the postoperative perigraft seroma appearance and subsequent corticosteroid administration predisposed this patient to pseudoaneurysm development, tissue glue usage was also considered.

Keywords: Aortic pseudoaneurysm; Aortic false aneurysma; Bentall procedure

\begin{abstract}
Abbreviations
APA: Aortic Pseudoaneurysm; TOE: Transesophageal Echocardiography; SJM: Saint Jude Medical; PCR: Polymerase Chain Reaction; DNA: Deoxyribonucleic Acid

\section{Introduction}

Aortic pseudoaneurysm (APA) is a rare but serious and complex complication of ascending aorta and/or aortic root prosthetic replacement which may lead to rupture and bleeding. APA following ascending aorta surgery is defined as a total or partial dehiscence of the vasular prosthesis from heart structures occurring after replacement of the ascending aorta. Although in the event of rupture, the mortality rate is high, patients often do not notice development of the pseuodaneurysm. If symptomatic, a pulsatile suprasternal mass, chest pain, dysphagia, and stridor may appear. The incidence is not wellknown nor risk factors or the natural history of aortic pseudoaneurysm. The mechanisms of APA formation are also unclear though suture line under tension or infectious endocarditis is presumed. APA develops late, usually years after operation. APA usually rupture, hence prompt surgical intervention is necessary.
\end{abstract}

\section{Case Report}

The 42 years old caucasian man suffered acute aortic dissection type $A$ and Bentall procedure with mechanical valve conduit (SJM graft prosthesis $25 \mathrm{~mm}$ ) was performed. Remaining aorta tissue and the suture lines were reinforced by tissue glue (BioGlue ${ }^{\oplus}$, CryoLife). The postoperative course was complicated by a recurrent fever of unknown etiology (completely negative laboratory tests). Infective endocarditis was considered, tha antibiotic therapy was administered. The transoesophageal echocardiography (TOE) was performed and revealed a collection of fluid surrounding the aortic graft with a tendency to progression (Figure 1). Explorative redo surgery was indicated and confirmed the sterile perigraft seroma, which recurred in the postoperative period. Extensive laboratory examination did not reveal either autoimmune or allergic disease; even the allergy to bovine collagen used int the manufacture of graft was tested. Then we administered the oral cortocosteroids. Therefore the clinical status has promptly improved and perigraft seroma slowly resorbed. The patient was discharged with normal echocardiographic findings. 10 months later he was admitted to the emergency department with pneumonia and sepsis. We performed the TOE imaging, which revealed depression of left, as well as, right ventricular systolic function and an aortic pseudoaneurysm which was caused by dehiscence of graft prosthesis in a non-coronary sinus. During cardiac systole the graft was significantly compressed by the pseudoaneurysmal sac (Figure 2).

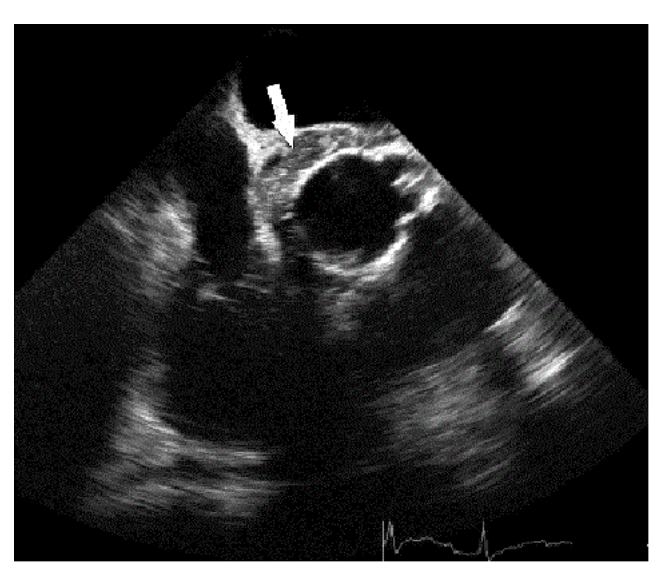

Figure 1: Perigraft collection after first Bentall procedure (indicated by arrow).

The clinical status was complicated by acute heart failure with low cardiac output due to septic cardiomyopathy. We considered APA as the possible source of sepsis due to its frequent infectious etiology, and the redo surgery was performed again, with technical difficulties. The pseudoaneurysmal sac surrounded more than half of the 
Citation: Hanak V, Troubil M, Santavy P, Lonsky V (2016) Pseudoaneurysm of the Ascending Aorta Following Bentall Procedure. J Cardiovasc Dis Diagn 4: 254. doi:10.4172/2329-9517.1000254

Page 2 of 3

circumference of the aortic graft but there were no signs of active or previous endocarditis (Figure 3 ).

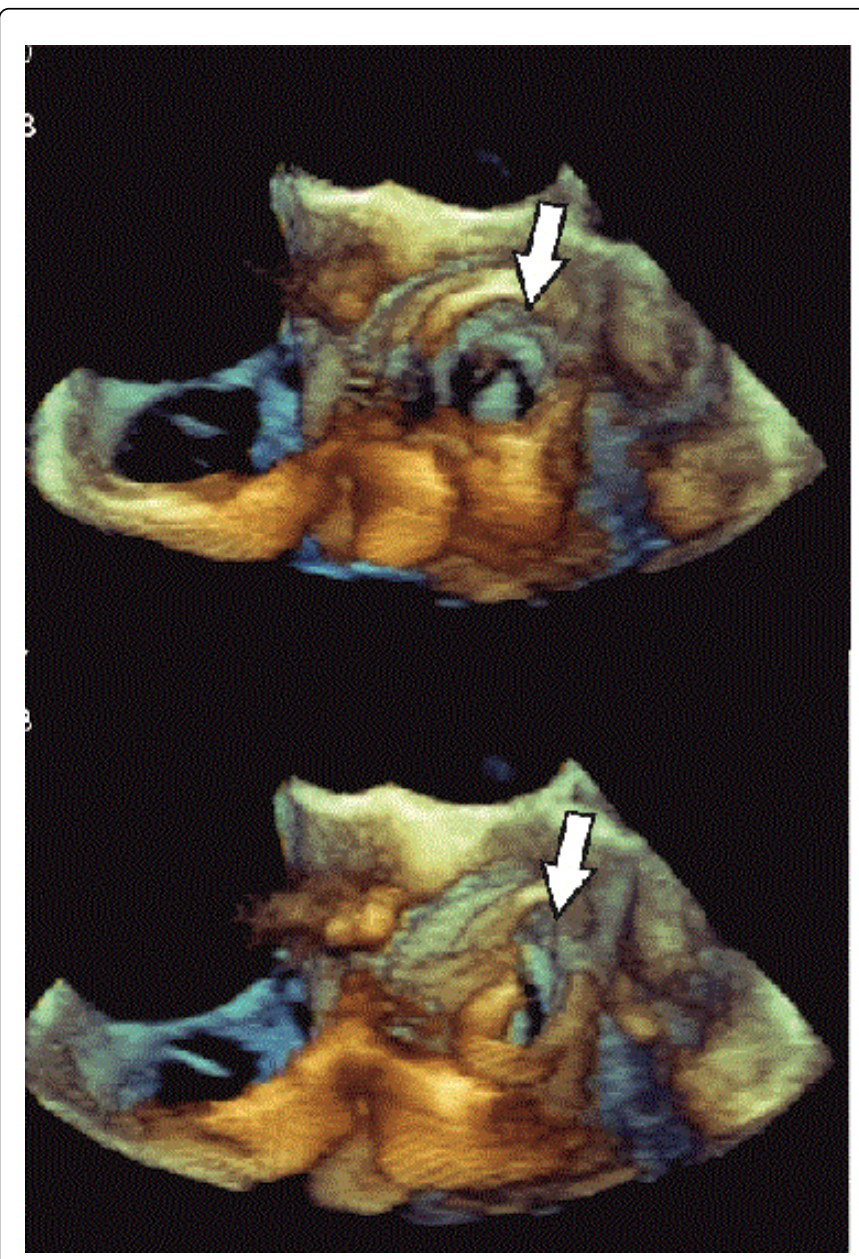

Figure 2: 3D TOE showed systolic compression of the aortic graft by pseudoaneurysm (indicated by arrow), causing low cardiac output and heart failure.

Original implanted mechanical conduit with APA sac was resected, coronary ostia buttons were released and re-Bentall operation was performed. The resected graft was analyzed using the PCR method, which did not reveal bacterial DNA. Patient recovery was long and complicated by pericardial tamponade, requiring another surgery Finally, he was discharged stabilized and one year after reoperation he was clinically well, except for depression.

\section{Discussion}

Aortic pseudoaneurysm formation is considered a major complication of surgery on the ascending aorta. The mechanism of the APA formation is not clear. It may be a sequelae of suture line tension, graft infection, excessive use of biologic glue [1,2] or persistent bleeding into the space surrounding the aortic graft [3]. Potential sites for APA formation are aortic and coronary ostial suture lines, aortotomy, aortic cannulation sites and proximal or distal aortic suture sites $[3,4]$. The incidence is unknown. The retrosopective study of Mohammadi [5] showed an incidence as high as 3\% of ascending aorta surgery survivors. Typically, the onset of APA presentation is months but more often years after the surgery [4,6]. About $40 \%$ of patients were asymptomatic in the retrospective analysis of Malvindi [4] but only 7\% in Mohammadi's analysis [5].

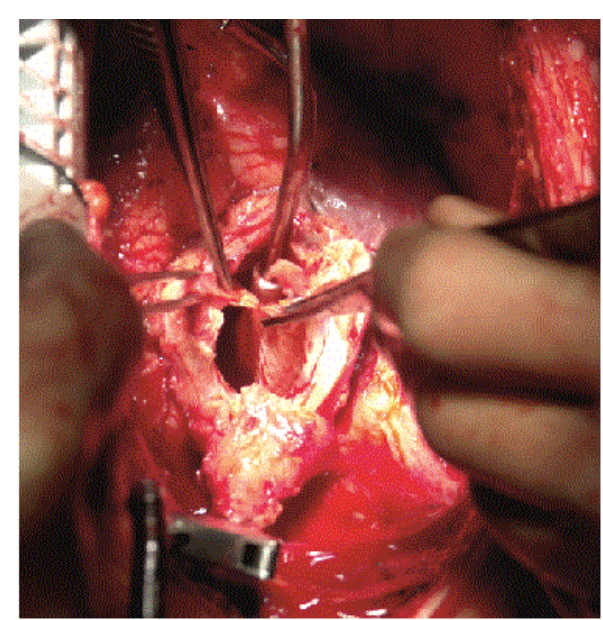

Figure 3: Suction device inserted in pseudoaneurysmal sac.

If symptomatic, pulsatile suprasternal mass, chest pain, dyspnea, stridor, myocardial ischemia, fever or septicaemia may appear $[3,4]$. APA also often compresses the superior vena cava, causing symptoms such as edema of the head, neck and arms, jugular veins distension, dyspnoea or dysphagia. In our case, APA also compressed the aortic graft prosthesis and presumably also decreased cardiac output. Although often mostly asymptomatic, this disease is still lifethreatening. The infectious cause of the aortic pseudoaneurysm after cardiac surgery is widely accepted. Katsumata et al. report persistent febrile illnes after the primary operation in 6 of 10 patients reoperated for the APA, operative tissue culture detected microbiological agent in only 3 cases (twice Corynebacterium sp., Staphylococcus sp. in one case) [7], Dumont et al. confirm infectious cause in 6 of 8 patients (all Staphylococcus sp.) [8]. Despite the expected infectious cause, there was no microbiological agent confirmed in our case. We assume the excessive use of antibiotics as the possibility of negative laboratory tests, but on the other hand, there was negative PCR analysis too. The use of corticosteroids after cardiac surgery in specific cases is common, and the Cappabianca meta-analysis even revealed, that steroid prophylaxis may reduce morbidity after cardiac surgery and does not increase the risk of postoperative infections [9]. Our experiences with the corticosteroids use are similar, e.g. in the postpericardiotomy syndrome therapy and we have seen no significant increase of postoperative infections or allogenic implanted material rejection. Dispite this, corticosteroid therapy in our case was probably one of the factors of graft rejection.

\section{Conclusion}

The presence of APA should be considered in all patients with previous aortic surgery and the symptoms listed above. In our case, the coincidence of pneumonia with sepsis led to the discovery of the APA. We presumed postoperative perigraft seroma appearance and subsequent corticosteroid administration predisposed the patient to pseudoaneurysm development, adverse reaction to tissue glue was also considered. 
Citation: Hanak V, Troubil M, Santavy P, Lonsky V (2016) Pseudoaneurysm of the Ascending Aorta Following Bentall Procedure. J Cardiovasc

Page 3 of 3

\section{Acknowledgements}

Except for the authors there was no person who substantially contributed towards the manuscript. Vladimir Lonsky and Petr Santavy performed the operations, Vaclav Hanak was the main author and wrote the article, Martin Troubil did the echocardiogram and was an attending cardiologist. All authors have read and approved the final manuscript.

\section{Consent}

Written informed consent was obtained from the patient for publication of this Case report and any accompanying images.

\section{Competing interests}

The authors declare that they have no competing interests.

\section{References}

1. Kirsch M, Ginat M, Lecerf L, Houël R, Loisance D (2002) Aortic wall alterations after use of gelatin-resorcinol-formalin glue. Ann Thorac Surg 73: 642-644.

2. Bingley JA, Gardner MA, Stafford EG, Mau TK, Pohlner PG, et al. (2000) Late complications of tissue glues in aortic surgery. Ann Thorac Surg 69: 1764-1768.
3. Sullivan KL, Steiner RM, Smullens SN, Griska L, Meister SG (1988) Pseudoaneurysm of the ascending aorta following cardiac surgery. Chest 93: 138-143.

4. Malvindi PG, van Putte BP, Sonker U, Heijmen RH, Schepens MA, et al. (2013) Reoperation after acute type a aortic dissection repair: a series of 104 patients. Ann Thorac Surg 95: 922-927.

5. Mohammadi S, Bonnet N, Leprince P, Kolsi M, Rama A, et al. (2005) Reoperation for false aneurysm of the ascending aorta after its prosthetic replacement: surgical strategy. Ann Thorac Surg 79: 47-152.

6. Kouchoukos NT, Kulik A, Castner CF (2013) Clinical outcomes and fate of the distal aorta following 1-stage repair of extensive chronic thoracic aortic dissection. J Thorac Cardiovasc Surg 146: 1086-1091.

7. Katsumata T, Moorjani N, Vaccari G, Westaby S (2000) Mediastinal false aneurysm after thoracic aortic surgery. Ann Thorac Surg 70: 547-552.

8. Dumont E, Carrier M, Cartier R, Pellerin M, Poirier N, et al. (2004) Repair of aortic false aneurysm using deep hypothermia and circulatory arrest. Ann Thorac Surg 78: 117-120.

9. Cappabianca G, Rotunno C, de Luca Schinosa LT, Ranieri VM, Paparella D (2011) Protective effects of steroids in cardiac surgery: a meta-analysis of randomized double-blind trials. J Cardiothorac Vasc Anesth 25: 156-165. 